\title{
Psychological well-being and quality of life in the clinical approach in Crohn's disease
}

Rodrigues AL, Pardini F. Psychological well-being and quality of life in the clinical approach in Crohn's disease. Arq Gastroenterol. 2019;56(2):111-2.

Experience from clinical practice, based on more comprehensive and integrated models of personal characteristics in diseased populations, shows that there is a positive correlation between psychological well-being and mortality-related demographic indices in these groups. It also shows the importance of increasing their resilience and well-being, regardless of their illness ${ }^{(1)}$.

This knowledge has been developed and deepened extensively, so much so that in PubMed one can see an approximately 300\% increase in this century in publications related to psychological well-being.

Regarding Crohn's disease in its various and complex clinical expressions, and its prevalence of $1 / 1000$ in the population of the $\mathrm{West}^{(2)}$, the state of São Paulo, Brazil, with 5.65 cases per 100,000 inhabitants ${ }^{(3)}$, with the increased incidence and prevalence of the disease in the past 50 years, and its important repercussions on the overall health of carriers, we have also observed in the medical literature a significant increase in the theme of psychological wellbeing and quality of life in the clinical approach to these patients.

This scientific interest results from the need to highlight the bio-psychosocial, that is, human aspects of the disease process, and the interdisciplinary care that these patients, due to their specific conditions, demand. Therefore, the interrelationship between these aspects becomes evident, and its interference in the expression of the activity of this disease, a condition shown by Burrill Bernard Crohn himself; In 1929, in a famous article published in the March 1930 Bulletin of the New York Academy of Medicine (The Psychoneuroses Affecting the Gastrointestinal Tract) ${ }^{(4)}$, and corroborated by Drossman $(1998)^{(5)}$ and, among others, by Sgambeto, Miranda, Ronaldo and Romano (2017) ${ }^{(6)}$.

It is worth noting that such contents have always been emphasized by the founder of the Archives of Gastroenterology journal, Prof. Dr. José Fernandes Pontes, in his clinical practice, research and teaching of Psychosomatic Medicine since the early 1960s.

This issue of Archives of Gastroenterology publishes the article, "Relationship among psychological well-being, resilience and coping with social and clinical features in Crohn's disease patients"(7), where the authors point out, in a very timely manner, the increased incidence and prevalence of inflammatory bowel diseases, with attention to Crohn's disease. Confirming our point of view, this increase cannot be explained solely by the wealth of evolutionary theories, and therefore just by elementary biology, immunology and other complex multifactorial etiopathogenic mechanisms, among them the pure psychological stress, but what other factors would be implicated in its triggering and polymorphic evolution.

The authors' proposal, through the approaches analyzed, investigates the direct influence of the disease on the patients' quality of life - which compromises their psychological well-being and demands coping and resilience efforts, with repercussions for the course of their evolution and new prospects for clinical treatment. Such evidence suggests, according to the authors and the referenced scientific literature, that health professionals concerned with and interested in the complexity, personal performance and conditions of psycho-affective comfort of these patients should assess and monitor their psychological well-being, providing them with adequate support in health care from a bio-psychosocial perspective.

This approach should result in the patient being encouraged to develop coping strategies for the clinical diagnosis and interpretation of lifestyle conditions of these individuals with Crohn, who frequently suffer threatening, often prolonged and limiting physical repercussions, with therapeutic control and response atypical and unpredictable, as well as the inevitable consequences for their psychosocial dynamics. On the other hand, the findings of this study, with the methodology and instruments employed, indicate that the social factors assessed, such as gender, marital status, level of schooling, presence of children, and cultural, social, economic, labor, religiousness or spirituality factors, among others, have a more significant influence on coping possibilities, resilience efficiency and, as a consequence, on psychological well-being, than the clinical aspects or conditions in which such individuals find themselves. Therefore, the goal is to focus on a dynamic perspective on the human being, with specific attention to the living conditions of each person.

The proper use and interpretation of the concepts applied to the group of patients studied in this paper permits a comparative analysis with different groups studied by other authors, richly highlighted in extensive and competent bibliographical references, in conceptual aspects about health and stress, psychological wellbeing, coping strategy and resilience, as well as highlighting its application in groups of patients with ulcerative colitis, Crohn's disease and other intestinal diseases, as well as other dermatological and cardiovascular entities.

We stress as the highlight of this work (in which the sample size and the non-analysis at various stages of the nosological entity in question weigh) its basic goal of a more integrated approach of clinical aspects, with humanized attention to the characteristics of emotional, socioeconomic, cognitive behavior, cultural and environmental aspects of the patients - which allows for a more complex involvement of the professionals involved, aiming at the promotion of and attention to more promising and positive health actions.

Avelino Luiz RODRIGUES ${ }^{1}$ Fernando PARDINI ${ }^{2}$ 
Rodrigues AL, Pardini F. Bem estar psicológico e qualidade de vida na abordagem clínica da doença de Crohn. Arq Gastroenterol. 2019;56(2):111-2.

\section{REFERENCES}

1. Chida Y, Steptoe A. Positive psychological well-being and mortality: a quantitative review of prospective observational studies. Psychosom Med. 2008;70:741-56.

2. Gasparetto M, Guariso G. Highlights in IBD Epidemiology and its natural history in the paediatric age. Gastroenterol Res Pract. 2013;2013:829040.

3. Victoria CR, Sassak LY, Nunes HR. Incidence and prevalence rates of inflammatory bowel diseases, in midwestern of São Paulo State, Brazil. Arq. Gastroenterol. 2009;46:20-5.

4. Crohn BB. The psychoneuroses affecting the gastro-intestinal tract. Bulletin of the New York Academy of Medicine. 1930; volume VI - No3. Annual graduate fortnight Functional and Nervous Problems in Medicine and Surgery October, 1929.

5. Drossman DA. Gastrointestinal illness and the biopsychosocial model. Psychosom Med. 1998;60:258-67.

6. Sgambato D, Miranda A, Ranaldo R, Federico A, Romano M. The role of stress in inflammatory bowel diseases. Curr Pharm Des. $2017 ; 23: 3997-4002$.

7. Acciari AS, Leal RF, Coy CSR, Dias CC, Ayrizono MLS. Relationship among psychological well-being, resilience and coping with social and clinical features in Crohn's disease patients. Arq Gastroenterol. 2019;56:131-40. 